\section{PYRAMIDEN ¿EDIFICIOS PARA DERRIBAR O PARA RENOVAR?}

128-7

El bloque Pyramiden está situado diagonalmente frente al rascacielos de la Delegación de Hacienda en el centro del distrito de Söder. ¿Quién sabe algo de él? ¿Cuántas personas, de las decenas de millares que pasan delante de él todos los días le echan algo más que una mirada distraida? Pyramiden es un viejo bloque que apenas llama la atención. No tiene ningún estilo uniforme de construcción; no contiene ningún edificio protegido por razones de interés cultural ni existe ninguna historia notable relacionada con él. No, Pyramiden es uno de los tantos bloques típicos de residencias de obreros en Söder, cuya historia es la de sus residentes.
La mayoria de los edificios se construyeron entre 1890 y 1920 y constan de casas que dan a la calle, casas en la parte posterior, con un patio en medio y los mismos patios, estrechos, apretados y rodeados de muros. Este era el estilo de construcción del periodo, estrecho y angosto. Lo mismo se aplica a los apartamentos; había muchos en cada casa y eran pequeños. La razón de ello era el intento de facilitar casa propia a todos los que estaban obligados a vivir como inquilinos. Con el transcurso de los años, muchas de las propiedades han sido modernizadas parcialmente y unas pocas han sido derribadas para dejar paso a nuevas casas totalmente modernas. Pero se ha descuidado el mantenimiento en la mayoría de las casas y éstas se han vuelto viejas y cada vez más pasadas de moda.

En los años 1950 y al principio de los 60, el concepto de reurbanización significaba casi siempre demolición y construcción de nuevos inmuebles. Las compañias privadas de construcción empezaron a comprar propiedades viejas para derribar-

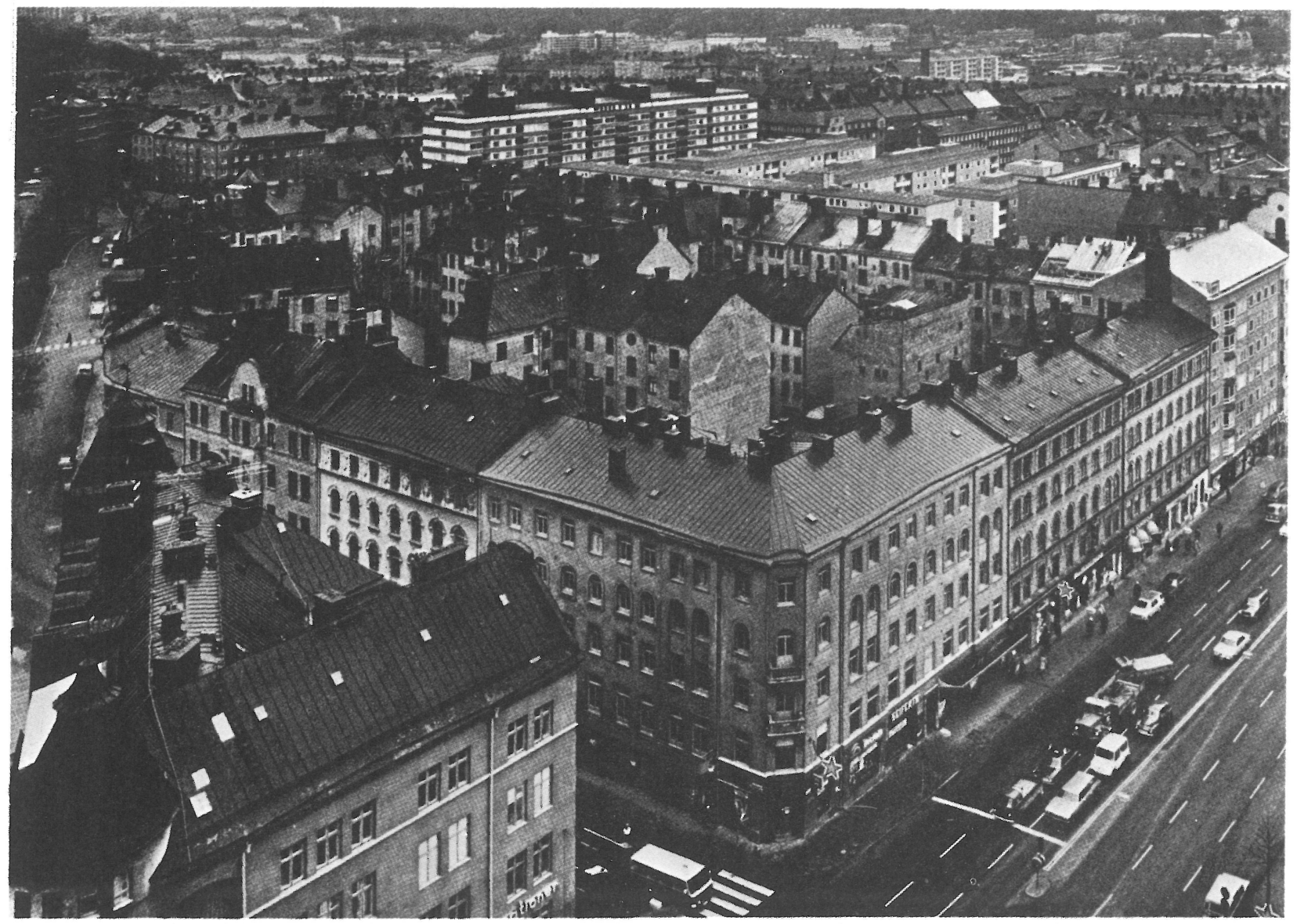

El bloque Pyramiden, propiedad en ruinas cerca de Gögatan en Söder. 
las y sustituirlas por nuevas casas y muchas veces bloques de oficina y tiendas.

Parecía que éste iba a ser el destino de Pyramiden. La mayor parte de los bloques fue comprada por una compañía privada con la intención de derribar las casas viejas y sustituirlas por bancos, oficinas y almacenes.

Pero Pyramiden se salvó de los bulldozers cuando la Svenska Bostäder adquirió 14 de las 16 casas de bloques en diciembre de 1972. Ahora bien, no se trataba de demolición sino de renovación. Pyramiden es el primer proyecto de más importancia de la compañía en reurbanización de propiedad residencial.

\section{Los métodos utilizados}

Cuando se emprende un trabajo de renovación de estas dimensiones, uno se enfrenta constantemente con problemas humanos y técnicos. Puede tratarse de facilitar información a los habitantes que han oído rumores acerca de los planes de renovación, pero también puede tratarse de resolver el problema de instalar un ascensor de modo aceptable en una propiedad donde hay poco espacio.

\section{Lo normal antes de la renovación}

La mayoría de los apartamentos estaban totalmente anticuados. No tenía calefacción central, ni agua caliente ni ducha o baño y el aislamiento térmico era ineficaz con ventanas de un solo cristal, entre otros factores.

Algunas de las casas habian sido modernizadas parcialmente, con agua caliente, pero con baños en los áticos. Un par de casas eran totalmente modernas, con agua caliente, baño/ducha y un ascensor.

Las dimensiones disponibles eran escasas. Los apartamentos eran numerosos, pequeños y angostos.

\section{Tamaño de los apartamentos antes de la renovación}

\begin{tabular}{|c|c|}
\hline & Número \\
\hline Una sola habitación $\ldots . . . \ldots \ldots \ldots \ldots \ldots \ldots . . . . . . .$. & 13 \\
\hline habitación más cocina ................. & 211 \\
\hline 2 habitaciones más cocina ............... & 144 \\
\hline 3 habitaciones más cocina .. & 40 \\
\hline habitaciones más cocina .. & 7 \\
\hline habitaciones más cocina.. & 4 \\
\hline Total & 419 \\
\hline
\end{tabular}
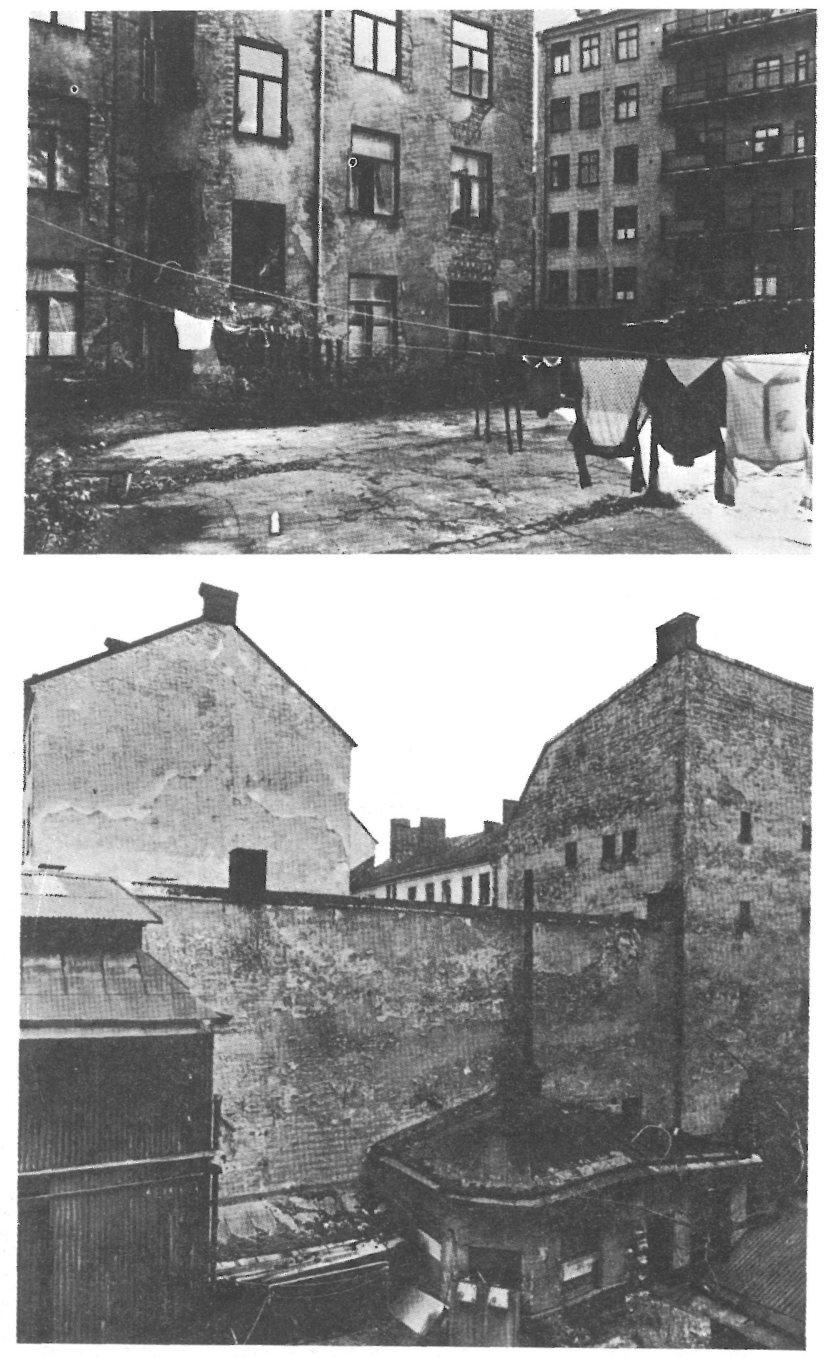

Antes de la renovación.

\section{¿Qué será lo normal después de la renovación?}

Con el fin de mejorar el espacio disponible se han ido juntando ciertos apartamentos. Partiendo de 419 pequeños apartamentos se obtendrán 239 residencias modernas con espacio suficiente para familias con hijos.

\section{Tamaño del apartamento después de la renovación}

\begin{tabular}{|c|c|}
\hline & Número \\
\hline 1 habitación más cocina ........................ & 29 \\
\hline 2 habitaciones más cocina $\ldots . . . . . . . . . . . . . .$. & 60 \\
\hline 3 habitaciones más cocina .................... & 95 \\
\hline 4 habitaciones más cocina .................... & 49 \\
\hline 5 habitaciones más cocina .................... & 6 \\
\hline Apartamentos en nueva propiedad ........... & 75 \\
\hline
\end{tabular}


Informes de la Construcción/355-356

Todos los edificios tendrán calefacción central y las residencias dispondrán de agua caliente, baño y servicio. Las cocinas se repararán y equipararán con accesorios totalmente modernos. Se tendrá que realizar una inspección general de los edificios. Si es preciso habrá que reparar los encofrados de la casa y en muchos casos renovar los tejados. Los exteriores tendrán que ser renovados y enlucidos, se inspeccionarán las chimeneas y volverán a revestir con ladrillos y se instalarán ascensores siempre que exista posibilidad y el espacio necesario.

En el interior se tendrá que restaurar o reponer todo el maderamen. Se tendrán que volver a colocar las tuberias del agua y los cables eléctricos y pintar los techos y paredes.

También se tendrán que mejorar los alrededores de los patios. Los muros entre los patios serán demolidos y se derribarán asimismo cierto número de pequeños edificios industriales para que los patios sean mayores, tengan más luz y estén más abiertos. Pero se ha conservado un edificio muy hermoso que alberga salas de reunión, una lavandería y una sauna para los habitantes del bloque.

Además de eso, la totalidad de la planta baja del número 24 de Katarina Bangata se ha transformado en un centro diurno para niños, lo cual no es usual para este tipo de edificio.

\section{Problemas de reurbanización}

Antes de empezar a trabajar con un proyecto de renovación de esta envergadura, se tienen que resolver muchos problemas. La primera tarea consiste en coordinar los puntos de vista de los inquilinos, las autoridades y los propietarios acerca de cómo se tienen que renovar las casas y a qué nivel y además se tienen que realizar todas las inspecciones preliminares sin molestar demasiado a los inquilinos.

Cuando Svenska Bostäder adquirió Pyramiden muchos apartamentos estaban desocupados y los inquilinos se habian marchado.

Los que seguian viviendo ahi eran en su mayor parte jóvenes subarrendados o con un contrato de arrendamiento válido hasta la demolición transformado en un alquiler de tercera mano. Habian oído hablar de planes anteriores de demolición a los cuales se oponian con firmeza. Desconfiaban y se preguntaban con ansiedad qué pasaria con ellos.

Por consiguiente el primer encuentro informativo celebrado con ellos fue bastante agitado, para decirlo de modo suave. Pero se fue creando gradualmente una confianza mutua a partir del momento en que los inquilinos comprendieron que el trabajo de renovación y su evacuación y regreso se tenía que realizar sobre la base de acuerdo mutuo.

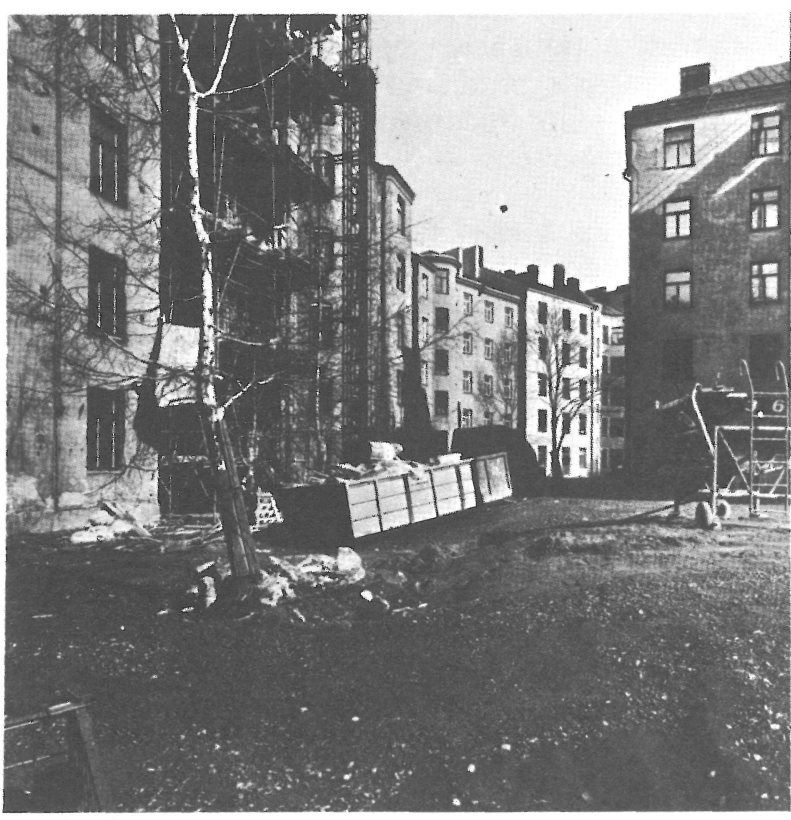

Renovación en curso.

Al mismo tiempo se seguía trabajando para resolver otro problema fundamental, el de adaptar los viejos encofrados de las cajas y la división de las habitaciones a los nuevos proyectos y división de los apartamentos.

Por desgracia, tres de las casas situadas frente a Götgatan tuvieron que derribarse ya que las condiciones de los cimientos eran muy malas. El cercano metro habia hecho que el nivel de las aguas freáticas descendiera y los soportes de madera sobre los cuales descansaban las casas habian sido atacados por bacterias y se habian podrido. Hubiera costado unas 800.000 coronas el intentar reforzar los cimiento lo cual no era factible desde un punto de vista económico.

\section{Problemas técnicos}

Es evidente que se encuentran constantemente problemas técnicos a la hora de renovar los edificios antiguos.

Existen diferencias entre la época de construcción y ahora en términos de protección contra incendios, aislamiento térmico y sonoro, suministro de agua y electricidad, sanitarios, refuerzos, etc.

En un bloque con una variedad tal de edificios, no se encuentran dos problemas iguales. Cada casa tiene su carácter propio y se deteriora a un ritmo diferente. Por ejemplo se pueden descubrir de pronto daños producidos por la podredumbre o el óxido para los cuales es preciso encontrar una soIución. En lugar de arreglar y reparar, deberán reponerse las zonas afectadas. Como se piensa que la casa dure otros cuarenta años, esto es lo más barato a largo plazo. 
El problema más difícil desde el punto de vista técnico es la instalación de ascensores en los edificios. Pero este problema se puede resolver, edificio por edificio, recurriendo a grandes dosis de inventiva y recursos.

De todos modos este tipo de trabajo difiere mucho de la construcción de nuevas residencias. Se trata de modernizar los apartamentos conservando en la medida de lo posible el carácter original de los edificios. Se procede con precaución y se trabaja como un artesano. Se conservan los detalles antiguos y elegantes y si han sido destruidos se sustituyen por detalles similares tomados de las casas que han sido derribadas.

\section{¿Qué ocurrió con los habitantes durante el trabajo de renovación?}

El trabajo de renovación realizado en Pyramiden fue tan amplio que los ocupantes se vieron obligados a mudarse a viviendas alternativas durante las obras. Como gran parte de los apartamentos estaban desocupados al comenzar los trabajos, no se produjo ningún problema. Fue posible encontrar nuevo alojamiento para los ocupantes en el mismo bloque o encontrarles otro piso dentro de los límites de la ciudad. Esto ocurrió con aquellos que habian subarrendado los apartamentos o arrendado los de tercera mano.

Todos aquellos que lo desearon pudieron volver cuando finalizó la renovación. Unicamente unos pocos ocupantes, por lo general gente mayor, prefirió, por varias razones, permanecer en el nuevo alojamiento facilitado fuera del bloque.

\section{¿A cuánto ascenderá la nueva renta?}

La renta se incrementó después de la renovación. Es de aproximadamente 125 coronas por metrc cuadrado y año en casas renovadas, es decir, es la misma que en apartamentos de nuevos edifi. cios.

\section{¿Quién vivirá aqui"?}

Uno de los objetivos del proyecto de renovación era que podría vivir cualquier categoría de personas. Aquí vivirán familias con hijos junto a pensionistas, parejas de mediana edad y estudiantes solteros.

Pero para darles una idea de quien viviria aquí y en qué condiciones financieras, hemos elegido un ejemplo ficticio muy típico de la zona y amueblado un apartamento de modo adecuado.

Gustav Adolf Norén, pensionista y viudo vive aquí en su apartamento preparado de dos habitaciones. Se crió en el distrito Söder, ha vivido aquí la mayor parte de su vida y está muy unido a la zona.

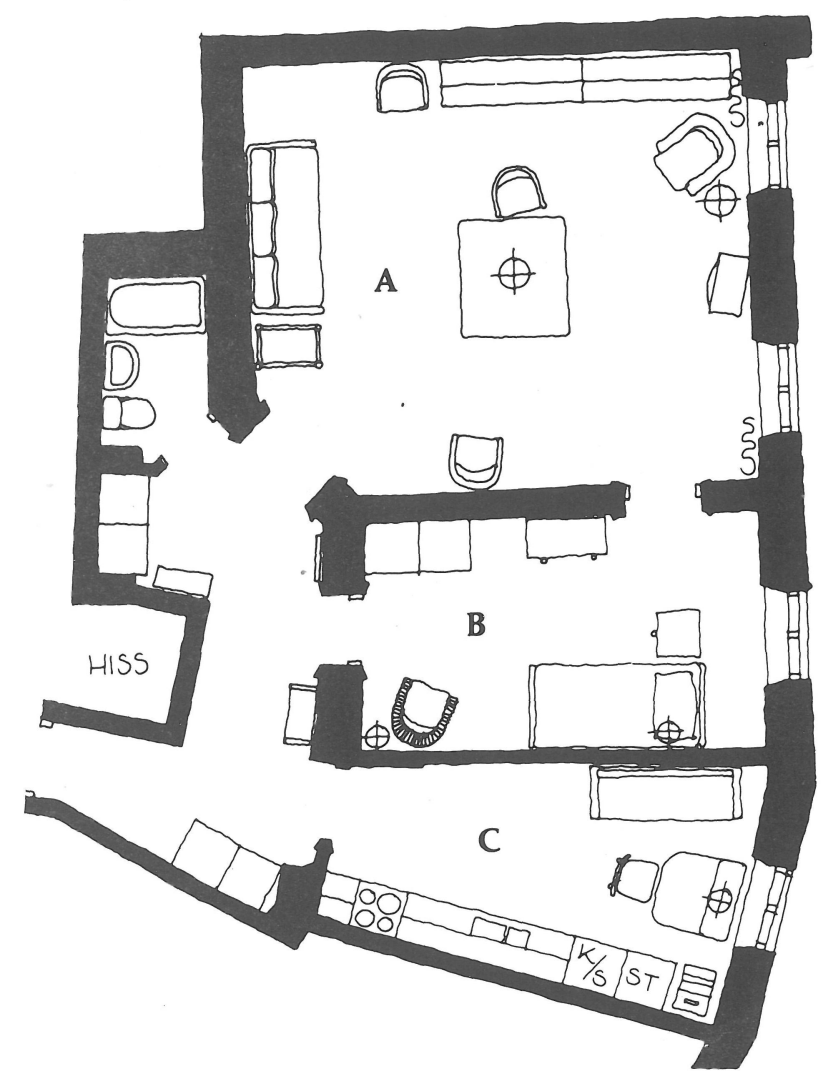

Su vida es tranquila y como es un viejo artesano, ayuda de vez en cuando a sus amigos y conocidos a realizar reparaciones de poca importancia.

Ha amueblado el cuarto de estar (A) con sus muebles antiguos familiares a los que ha añadido unas pocas piezas. Según podemos ver tiene mucho espacio y se ha organizado un pequeño "taller" donde puede sentarse y distraerse. Tiene también una silla confortable frente a la televisión y un amplio sofá en el que sus hijos pueden dormir cuando vienen a visitarlo. El dormitorio (B) es la habitación tranquila con una cama confortable. También hay un par de armarios que complementan las habitaciones en la entrada. En la cocina $(C)$ tiene los mismos muebles que ha tenido durante toda su vida. Entre otras cosas posee una pequeña mesa de alas abatibles y un sofá de cocina.

\section{Situación financiera de Gustav Adolf Norén}

Gustav recibe 792 coronas suecas de pensión por retiro, más 800 coronas suecas de suplemento, o sea, 1.592 coronas suecas por mes. Paga 205 coronas suecas de impuestos y le quedan a Gustav 1.387 coronas suecas por mes. El alquiler es de 726 coronas suecas por mes (625 de alquiler +74 de costes de calefacción).

La situación financiera de Gustav le da derecho a 672 coronas suecas por mes como subsidio de renta, lo cual le da una renta neta de $726-672=54$ coronas suecas por mes. 